\title{
Effect of Association Natural-Recycling Aggregates (Crushed Glass and Waste Tire) on Mechanical Properties of the Concrete
}

\author{
Mamery Adama Serifou, Olivier Moro Boffoué, Paul Sery Obre Jolissaint, Clement Koffi Kouadio, \\ Edjikémé Emeruwa
}

Department of Earth Sciences and Mineral Resource, Geomaterial Laboratory, Université Félix Houphouët Boigny, Abidjan, Côte d’Ivoire

Email address:

smadamsdedjen@yahoo.fr (M. A. Serifou)

\section{To cite this article:}

Mamery Adama Serifou, Olivier Moro Boffoué, Paul Sery Obre Jolissaint, Clement Koffi Kouadio, Edjikémé Emeruwa. Effect of Association Natural-Recycling Aggregates (Crushed Glass and Waste Tire) on Mechanical Properties of the Concrete. International Journal of Materials Science and Applications. Vol. 6, No. 1, 2017, pp. 28-31. doi: 10.11648/j.ijmsa.20170601.14

Received: October 31, 2016; Accepted: November 11, 2016; Published: January 12, 2017

\begin{abstract}
This study relates to the use of the industrial waste as substitute to the natural aggregates. It relates to two types of waste: Crushed glass and waste tires. These wastes were incorporated into concrete for a partial substitution of the aggregates in the proportions of $5 \%, 10 \%, 15 \%, 20 \%, 25 \%$ and $30 \%$ for the same matrix (mortar). The compressive strength and the mode of rupture are compared. The results show a decrease of compressive strength when the proportion of waste increases. Moreover, the compressive strength of concrete of used tire is lower than that of the concrete of crushed glass. Variation of the mode of rupture between these two types of concrete was also observed.
\end{abstract}

Keywords: Concrete, Compressive Strength, Crushed Glass, Industrial Waste, Recycling, Waste Tire

\section{Introduction}

Certain waste constitutes traps for water where the mosquitos responsible for many diseases such as malaria can reproduce. The collection and especially the creation of a viable economic activity of recycling this waste can bring a durable solution.

Also, with a view on economy and protection of the natural resources like crushed rocks and alluvial aggregates, a study aiming at reducing their quantity in the concrete is carried out. It consists in making a partial substitution of natural aggregates (crushed granite) by various proportions of waste and at studying their effect on the mechanical properties of these concretes.

Thus, an association of crushed glass on the one hand and used tire on the other hand are carried out with the natural gravels by a substitution from $5 \%$ to $30 \%$.

The use of siliceous aggregates such as glass in the concrete involves a reaction of the concrete on the aggregate (alkali-silica reaction). An expansive gel is formed on the interface aggregate-paste and involves an embrittlement of material by creation of microscopic cracks. As Glass is mainly made up of silica, the recycling of glass in the concrete raises this problem. If glass is crushed into fine powder, it can react with the portlandite (pozzolanic reaction) and form new Calcium Silicate Hydrate (CSH), which improves resistance of the concrete.

Many authors like [1-5] located the critical size of glass aggregate between 0.038 and $1.18 \mathrm{~mm}$. Over those dimensions the alkali-silica reaction occurred (ASR). The use of crushed glass as gravels would thus induce an alkali-silica reaction whatever the selected reference. However, this reaction (ASR) occurs more than ten years later and also the importance of environmental problems caused by nonrecycling glass and the waste of used tires, on the protection of the natural resources justify this study.

\section{Materials and Methods}

\subsection{Materials}

Glasses used in this study are non-recycling bottles. They were collected from discharges in Abidjan. After a sorting, only the green bottles were used as according to [6], these 
bottles because of their low silica content will induce less ASR.

In Côte d'Ivoire, the main way of elimination of waste tires is incineration which produces an important quantity of $\mathrm{CO}_{2}$. To solve this situation, used tires were collected to be used as aggregates in this study. Tires and bottles are manually reduced into small pieces by cutting for the first and crushing for the other.

The grain size analyses of natural aggregates and glass were carried out by sifting according to (NF P 94-056 Standard) and the results are presented on figure 1 . That of the tire was carried out by measuring the median dimension of the parallelepiped aggregate and the mass of each one of them. Indeed because of the metal reinforcements of tire; it was very difficult to sieve the aggregates of tire. The curve was carried out starting from measurements taken on 116 samples for a total mass of $863 \mathrm{~g}$.

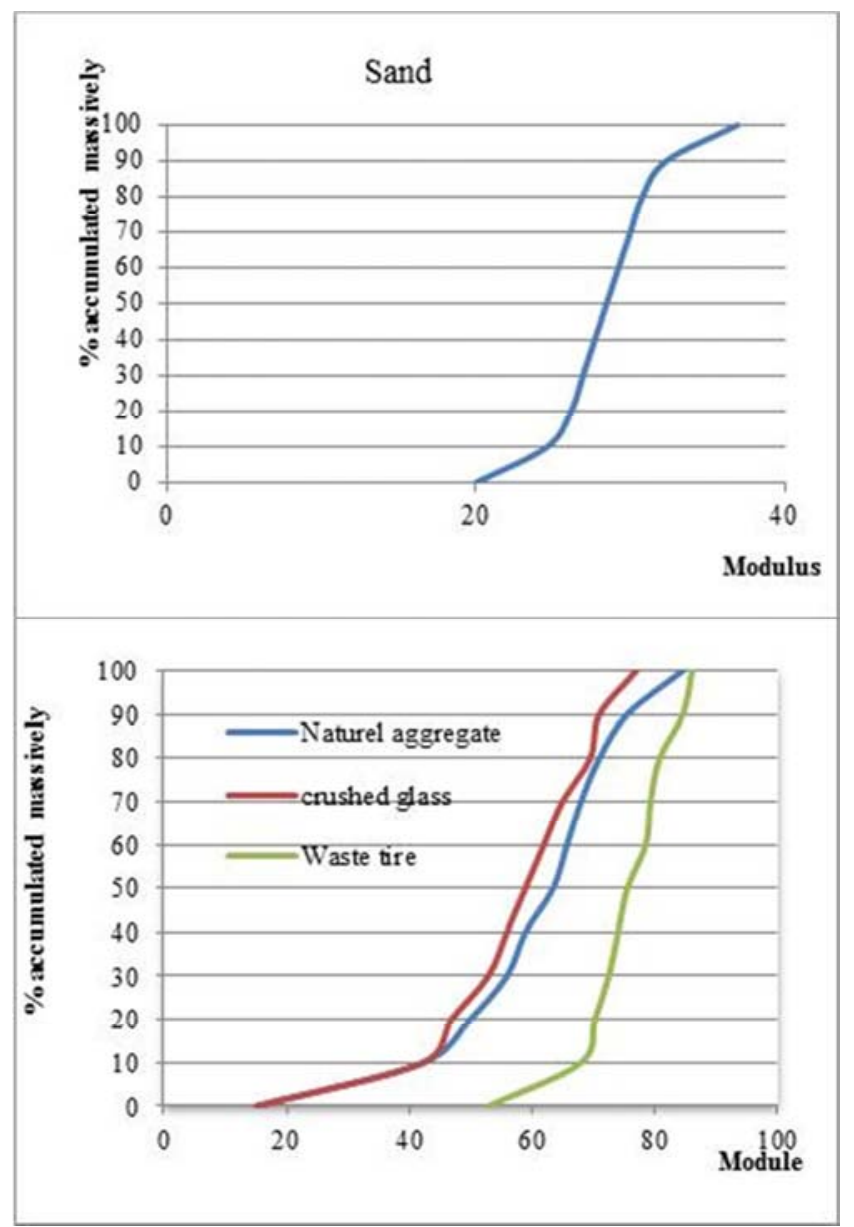

Figure 1. Curves grading (a) sand (b) aggregates.

\subsection{Methods}

\subsubsection{Elaboration of Concrete}

In order to study the effect of the volume of aggregates, concretes are elaborated like a mortar, in which content of aggregates in gradually increased. All concretes are similarly made.
Thus each mixture has the same quantities of cement, sand and the ratio water/cement is constant.

Table 1. Proportions of mixture.

\begin{tabular}{|c|c|c|c|c|c|c|c|}
\hline \multirow[t]{2}{*}{ Material } & \multicolumn{7}{|c|}{ Concretes } \\
\hline & $\mathbf{N}$ & $V_{5}$ & $V_{10}$ & $V_{15}$ & $\mathbf{V}_{\mathbf{2 0}}$ & $\mathbf{V}_{25}$ & $\mathbf{V}_{30}$ \\
\hline Cement (kg) & 16 & 16 & 16 & 16 & 16 & 16 & 16 \\
\hline Water (1) & 6 & 6 & 6 & 6 & 6 & 6 & 6 \\
\hline $\mathrm{W} / \mathrm{C}$ & 0,37 & 0,37 & 0,37 & 0,37 & 0,37 & 0,37 & 0,37 \\
\hline Sand (kg) & 16 & 16 & 16 & 16 & 16 & 16 & 16 \\
\hline $\begin{array}{l}\text { Natural } \\
\text { Aggregates (kg) }\end{array}$ & 14 & 13,3 & 12,6 & 11,9 & 11,2 & 10,5 & 9,8 \\
\hline $\begin{array}{l}\text { Recycling } \\
\text { aggregates (kg) }\end{array}$ & - & 0,7 & 1,4 & 2,1 & 2,8 & 3,5 & 4,2 \\
\hline Substitution (\%) & 0 & 5 & 10 & 15 & 20 & 25 & 30 \\
\hline Vgp & 0 & 6,20 & 6,34 & 6,48 & 6,62 & 6,76 & 6,90 \\
\hline Vgv & 0 & 6,08 & 6,09 & 6,11 & 6,13 & 6,15 & 6,16 \\
\hline
\end{tabular}

Vgp: Volume of used tire in concrete

Vgv: Volume of crushed glass in concrete

The concrete samples of $16 \times 32 \mathrm{Cm}^{2}$ are made in accordance with the standard P 13-451. They are unmolded after 24 hours. Moreover, the conservation is done in a wet basin until maturation (28 days).

\subsubsection{Characterization of Samples}

After the 28 days of maturation the bulk density of the samples was determined by measurement of their mass and dimensions.

The compressive strength was also determined according to standard NF P 18-406.

\section{Results and Discussion}

\subsection{Compressive Strength and Bulk Density}

Table 2 and figures 2, 3 present the value of compressive strength test and the average value of bulk density for each proportion of concretes.

Table 2. Values of compressive strength and density.

\begin{tabular}{|c|c|c|c|c|c|c|c|}
\hline PA (\%) & \multicolumn{2}{|c|}{ CS (MPa) } & & A & ET & CV & D \\
\hline \multicolumn{8}{|c|}{ Concrete of natural aggregates and crushed glass } \\
\hline 0 & 36,2 & 34,5 & 36,1 & 35,6 & 0,9 & 0,047 & 2,3 \\
\hline 5 & 18,9 & 20,4 & 21,8 & 20,4 & 1,5 & 0,171 & 2,2 \\
\hline 10 & 20,6 & 22,3 & 18,1 & 20,3 & 2,1 & 0,317 & 2,2 \\
\hline 15 & 22,6 & 22,4 & 21 & 22 & 0,9 & 0,201 & 2,3 \\
\hline 20 & 18,8 & 23,1 & 24,6 & 22,2 & 3,0 & 1,357 & 2,2 \\
\hline 25 & 18 & 18,4 & 18,7 & 18,4 & 0,4 & 0,089 & 2,3 \\
\hline 30 & 20,4 & 16,4 & 17,9 & 18,2 & 2,0 & 0,289 & 2,2 \\
\hline \multicolumn{8}{|c|}{ Concrete of natural aggregates and waste tire } \\
\hline 0 & 36,2 & 34,5 & 36,1 & 35,6 & 0,95 & 0,027 & 2,3 \\
\hline 5 & 14,7 & 10,4 & 12,5 & 12,5 & 2,15 & 0,172 & 2,2 \\
\hline 10 & 06,9 & 10,8 & 08,5 & 08,7 & 1,96 & 0,224 & 2,1 \\
\hline 15 & 07,6 & 05,7 & 06,2 & 06,5 & 0,98 & 0,152 & 2,1 \\
\hline 20 & 06,3 & 04,9 & 07,1 & 06,1 & 1,10 & 0,180 & 2,1 \\
\hline 25 & 05,4 & 06,1 & 05,8 & 05,8 & 0,35 & 0,070 & 2,0 \\
\hline 30 & 03,8 & 04,1 & 04,4 & 04,1 & 0,30 & 0,073 & 1,9 \\
\hline
\end{tabular}

PA: proportion of aggregates; CS: compressive strength; A: average; ET: ecart type; CV: Coefficient of variation; D: density 


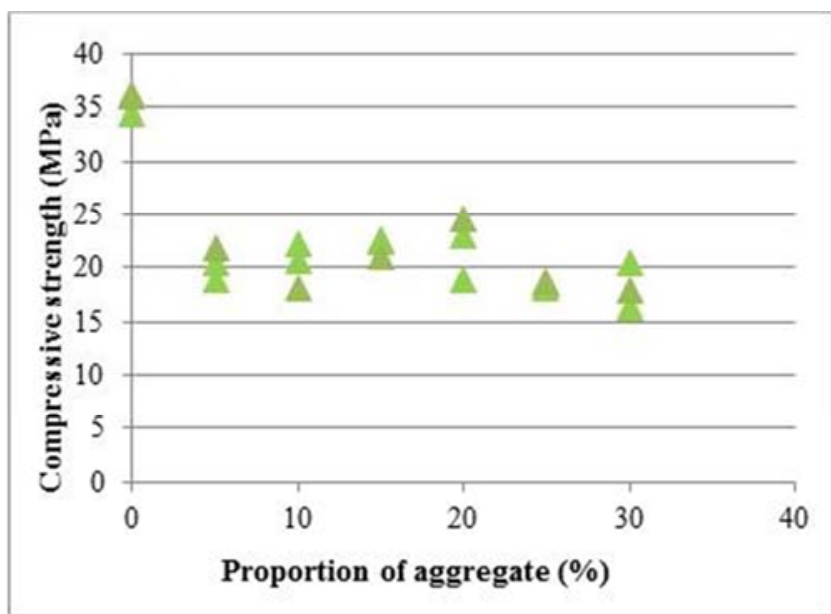

Figure 2. Compressive strength of the concrete according to the proportion of aggregate of glass.

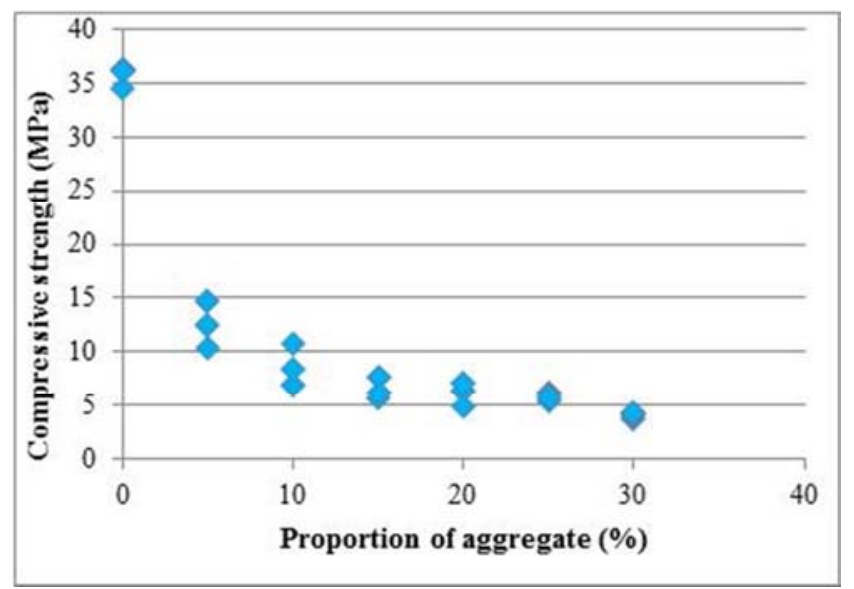

Figure 3. Compressive strength of the concrete according to the proportion of aggregate of tire.

Table 2 shows that compressive strength of the different samples decreases when the proportion of recycling aggregates increases.It can be explained by the low adherence between aggregates and mortar. Indeed the recycling aggregates used (glass and tire) have none absorbing and smooth surfaces. These surfaces prevent a good fixing of the mortar so application of load causes a fast separating of the mortar from aggregate [7-8].

For these authors, the decrease of compressive strength depends on the adherence of those aggregates to the mortar. However, for [9] it can be caused by the shape of aggregates. [10] show that the compressive strength decrease linearly according to the ratio of replacement.

The over reason is the volume occupied by the recycling aggregates (table 1). Indeed, when the volume occupied by the aggregates increases, the quantity of mortar becomes insufficient to bind the aggregates suitably. That induces the creation contact between aggregates of different nature; that is to say contact between a stiff element (natural aggregates) and a less stiff element (tire or glass).This contact constitutes a weakness zone through which the crack can propagate.

Many authors, [11-17] estimate the loss of compressive strength between 21 and $99.95 \%$ compared to a concrete of reference.

For this study (substitution of $30 \%$ ) the loss of resistance is approximately $50 \%$ for crushed glass and $90 \%$ for waste tires.

Table 2 also shows that the bulk density of the concretes containing the glass aggregates is similar to that of the concretes of reference, on the other hand that of the concretes containing tire aggregates decreases with the increase in those aggregates. Thus, like [18-19], this study indicates that tire aggregates contribute to the lightening of the concretes by their low density.

\subsection{Influence of Nature of Recycling Aggregates on the Mode of Rupture of the Concretes}

The effect of this association is also observed on the samples of concrete after being submitted to a constraint. The figure 6 shows samples after compressive strength test.
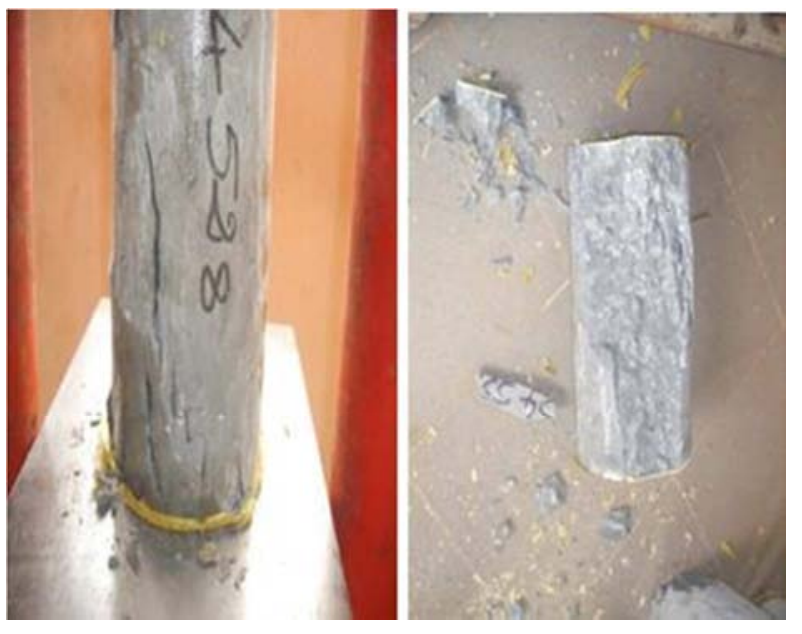

Figure 4. Samples after compressive strength test.

a. Concrete of natural aggregates and used tire

$b$. Concrete of natural aggregates and crushed glass

The concrete containing the association of waste tire and the natural aggregates (figure 4a) present vertical cracks but they are not dislocated. Whereas, the concretes containing the association of crushed glass and natural aggregates (figure $4 \mathrm{~b})$ are dislocated and exploded under the constraint (effect of brittleness of material). Indeed after the maximum constraint, compressive strength of used tire concrete decreases gradually indicating that the samples are not completely dislocated because of the presence of the rubber aggregates and can support loads post-rupture with increase in the deformations. Degradation is more significant for the concrete of crushed glass than the concrete containing of the rubber aggregates.

According to the observation, it can be notice that rubber attenuates the constraint and blocks cracking which weakens material. The aggregates of tire absorb energy associated to cracks propagation and behave like cracks stoppers.

\section{Application of the Concrete of TireThe}


tire concrete can be advantageous for special applications where the main request is not the mechanical properties, such as the production of sound barriers, terraces and platform.... According to [20] the association of used tire concrete can be used in applications where there is a need for weak penetration of chloride ions in structures and where the corrosion of the reinforcements must be avoided.

In spite of the bad compressive strength, the concretes of waste tire present obvious interest in all the applications where compressive strength is less of interest than the post rupture behaviour.

\section{Conclusion}

Partial substitution of the natural aggregates by crushed glass and used tires generates significant differences in the properties of the concrete, with consequences on durability. Tests carried out obviously show that the incorporation of the recycling aggregates involve a decrease of the compressive strength. Which can be explained by a low adherence of the waste tire and crushed glass aggregates to the matrix.

However, the compressive strength of crushed glass concrete is higher than those of used tire.

In spite of the decrease of compressive strength, the used tire concrete, under the constraint resist to cracking. Cracking which represents the main handicap of cementitious materials such as concrete. Lastly, an application of used tires concretes of would be the use for large surfaces more sensitive to the cracking and the structures of protection against the corrosion of the reinforcements.

\section{References}

[1] Rachida I., Martin C., Arezki T (2010). Etude des propriétés des bétons de verre. Technologie valorisation Vol. $16 \mathrm{~N}^{\circ} 5 / 6$, pp 70-77.

[2] Jin C., Meyer C. et Baxter S. (2000). "Glasscrete"-Concrete with glass aggregate, American concrete institute, Material Journal, $n^{\circ} 97$, pp.208-213.

[3] Yamada, K. et Ishiyama, S (2005). Maximum dosage of glass cullet as fine aggregate in mortar, dans Dhir, R. K. Newlands, Dyer, T. D. (2005) Achieving Sustainability in Construction, Proceedings of the International Conference Held at the University of Dundee, Scotland, UK on 5-7 July.

[4] Meyer, C., Baxter, S. et Jin, W (1996). Alkali-silica reaction in concrete with waste glass as aggregate, Materials for a New Millennium, Proceedings of ASCE Materials Engineering Conference, Washington,, pp. 1388-1394. Cité dans [Rachida et al, 10].

[5] Lee G., Ling T. C., Wong Y. L., Poon C. S. (2011). Effects of crushed glass cullet sizes, casting methods and pozzolanic materials on ASR of concrete blocks. Construction and Building Materials, 25, pp 2611-2618.
[6] Topçu I., Boga A. et Bilir T. (2008). Alkali-silica reactions of mortars produced by using waste glass as fine aggregate and admixtures such as fly ash and Li2CO3. Waste Manage;28 (5), pp 84-878.

[7] Tung-Chai L., Chi-Sun P., et Shi-Cong K. (2011). Influence of recycled glass content and curing conditions on the properties of self-compacting concrete after exposure to elevated temperatures. Cement \& Concrete Composites, $18 \mathrm{p}$.

[8] Kou S-C. et Poon C-S. (2009). Properties of self-compacting concrete prepared with recycled glass aggregate. Cem Concr Compos 31 (2), pp 103-107.

[9] Polley C., Cramer S. M. et Rodolfo V (1998). Potential for using waste glass in Portland cement concrete, Journal of Materials in Civil Engineering, vol. 10, $\mathrm{n}^{\circ}$ 4, pp 210-219.

[10] Topçu I. B. et Mehmet C (2004). Properties of concrete containing waste glass. Cement and Concrete Research 34, pp 267-274.

[11] Batayneh, Malek K., Marie, Iqbal, and Asi, Ibrahim (2008). Promoting the use of crumb rubber concrete in developing countries - Waste Management - Vol. 28 - Numéro 11 - pp. 2171-2176.

[12] Khaloo, Ali R., Dehestani, M., and Rahmatabadi, P. (2008). Mechanical properties of concrete containing a high volume of tire-rubber particles - Waste Management - Vol. 28 Numéro 12- pp. 2472-2482.

[13] Li, Guoqiang, Garrick, Gregory, Eggers, John, Abadie, Christopher (2004). Stubblefield, Michael A., and Pang, Su Seng - Waste tire fiber modified concrete- Composites Part B: Engineering - Vol. 35 - Numéro 4 - pp. 305-312.

[14] Bravo, Miguel and de Brito, Jorge (2012). Concrete made with used tyre aggregate: durability-related performance Journal of Cleaner Production - Vol. 25 - Numéro 0- pp. 4250 .

[15] Fattuhi, N. I. and Clark, L. A. (1996). Cement-based materials containing shredded scrap truck tyre rubber - Construction and Building Materials - Vol. 10 - Numéro 4 - pp. 229-236.

[16] Ganijian, Eshmaiel, Khorami, Morteza, and Maghsoudi, Ali Akbar (2009). Scrap-tyre-rubber replacement for aggregate and filler in concrete - Construction and Building Materials Vol. 23 - Numéro 5- pp. 1828-1836.

[17] Toutanji H. A (1996). The use of rubber tire particles in concrete to replace mineral aggregates - Cement and Concrete Composites - Vol. 18 - Numéro 2 - pp. 135-139.

[18] Eldin N. N., et Senouci A. B. (1993). "Rubber tire particules as concrete aggregate". Journal of Materiel in civil Engineering, vol.5, No4, pp.478-496.

[19] Fedroff D., Ahmad S., and Savas B. Z. (1996) Mechanical properties of concrete with ground waste tire rubber. Transportation Research Board, No. 1532, pp.66-72.

[20] Oikonomou N. et Mavridou S. (2009). Improvement of chloride ion penetration resistance in cement mortars modified with rubber from worn automobile tires. Cement \& Concrete Composites, $40 \mathrm{p}$. 